Review Article

\title{
CRITICAL REVIEW OF THE DETERMINANTS OF MEDICATION ADHERENCE IN PATIENTS WITH DEMENTIA
}

\author{
LLOYD RICHARDSON, HANA MORRISSEY, PATRICK BALL \\ University of Wolverhampton, School of Pharmacy, United Kingdom \\ Email: hana.morrissey@wlv.ac.uk
}

Received: 28 Jan 2020, Revised and Accepted: 23 Mar 2020

\begin{abstract}
Objective: Medication adherence is a prominent issue in the general population; therefore, due to the nature of dementia, the risk of medication no adherence is even greater. Furthermore, there have been discrepancies regarding the impact of specific determinants on medication adherence as previous literature has cited conflicting information. This review aimed to identify the potential causative relationship of dementia that may result
\end{abstract} in medication non-adherence.

Methods: A meta-analysis of (15 primary research papers) was conducted to identify and assess the specific themes and determinants related to non-adherence, and their impact on medication adherence in those who were cognitively impaired.

Results: Four domains were established or developed upon review and risk of bias and risk of the summary table were created. A critical review undertaken to analyse various papers and their respective findings. Through the data analysis it was found that common themes could be established, such as Cognitive impairment, Disability, Mental illness and occasional forgetfulness to take their medication. The impact of each domain was expressed e. g. the predominant role of executive function and memory as well as non-adherence leading to delusional or suspicious thoughts.

Conclusion: The findings align with current literature. The caregiver aspect needs to be addressed more thoroughly and more investigations are required such as identifying underlying factors that may potentially result in influence.

Keywords: Cognitive impairment, Disability, Mental illness, Medication NON-adherence, Forgetfulness

(C) 2020 The Authors. Published by Innovare Academic Sciences Pvt Ltd. This is an open access article under the CC BY license (http://creativecommons.org/licenses/by/4.0/) DOI: http://dx.doi.org/10.22159/ijcpr.2020v12i3.38325. Journal homepage: https://innovareacademics.in/journals/index.php/ijcpr

\section{INTRODUCTION}

Adherence can be defined as; "the extent to which a person's medication-taking behaviour, following a diet and/or executing lifestyle changes-corresponds with agreed recommendations from a healthcare provider" according to the World Health Organisation (WHO) [1]. This ultimately suggests that if an individual abides by the recommendations that had been set by their healthcare provider, they are classed as adherent and if they do not follow those recommendations, they are then classed as non-adherent.

Medication adherence can be important to all the parties involved, due to the potential sequalae caused by non-adherence. "No adherence may limit the benefits of medicines, resulting in lack of improvement, or deterioration, in health "according to the UK national institute of clinical excellence (NICE). When patients do not disclose or recognise their non-adherence, this can lead to health professionals considering their current therapy to be ineffective and add new medications or cause the patient to deteriorate causing condition complications and hospital admissions. Both situations trigger more cost for both the individual and the health system "The economic costs are not limited to wasted medicines but also include the knock-on costs arising from increased demands for healthcare if health deteriorates "as stated by NICE [2].

The findings of non-adherence by the WHO (2003) has been further explored by Burnier and Egan [3] who stated that some patients may not accept the diagnosis while some patients may not understand the importance of controlling the severity of their illness which may result in a faster decline of their condition. It has been shown ${ }^{4}$ that around one third (33\%) of all patients stop taking their medication $10 \mathrm{~d}$ after initiation of long-term therapy and almost half (50\%) of those who do so, do it deliberately although their reasons vary. It has shown that only $16 \%$ continue to take their medications as directed. This demonstrates the important of addressing adherence going forward [4].

"Dementia is a progressive clinical syndrome characterised by a range of cognitive and behavioural symptoms that can include memory loss, problems with reasoning and communication, a change in personality, and a reduced ability to carry out daily activities such as washing or dressing" as defined by NICE [2].

The term dementia is an umbrella term and consists of Alzheimer's disease, which is the most prevalent type of dementia. Vascular dementia (VaD) is the second most common type, affecting around 150,000 people in the UK. Vascular dementia can be caused by strokes and transient ischaemic attacks. Dementia with Lewy bodies accounts for $10-15 \%$ of all cases of dementia. It occurs where there are deposits of alpha-synuclein that appear in nerve cells in the brain, however, it is not fully understood how this contributes to dementia.

Front temporal dementia (FTD) usually affects those aged around 45 to $54 \mathrm{y}$. This condition is usually caused by the death of nerve cells and pathways in the frontal and temporal lobes of the brain. Front temporal dementia is commonly associated with other neurological impairment such as Parkinson's disease or motor neurone disease [5].

Dementia currently affects approximately 850,000 people in the UK, with this fig. expected to rise above 1 million by 2025 and to $>2$ million by 2051 . In addition to this, 24.6 million people within the UK are aware of a family member or a close friend living with dementia, and 1 in 3 people within the UK will develop dementia within their lifetime. However according to Dementia Statistics Hub (2017)“ due to the gradual nature of dementia and the mild early-stage symptoms and the low diagnosis rate it is difficult to know the exact number of people living with dementia" which suggests that the true value may be substantially higher than has been estimated from determining the prevalence in different age groups and extrapolating [6].

There are stages of dementia, including early dementia in which the individual is deemed to be able to still function independently; however, these individuals may start to notice certain things such as having the inability to recall where they may have placed certain objects, experience certain personality 
changes and struggle to solve complex tasks [5]. Moderate dementia is where the individual may experience greater memory loss and require assistance with personal activities of daily living, such as bathing and dressing. Severe dementia is characterised by a loss of the ability to communicate, require full time assistance in regarding certain tasks [7]. These stages can further be divided into a further seven stages known as the functional assessment staging test [8].

Dementia can be diagnosed through physical examination, neurological examination and mental status tests. These come in various forms; the most commonly used is the standardized minimental state examination (SMMSE), which uses a 30-point scale and includes questions that examine memory and motor function skills [7]. The SMMSE stage- 1 consists of repeating certain words back. In stage- 2 the individual is asked to draw a clock. At stage 3 the individual is asked to repeat the words back that were mentioned in stage 1 . Finally, the healthcare professional who is conducting the examination utilises a clinical dementia rating scale where a score of 0 is normal, a score of $0.5-1$ is mild dementia a score of 2 is moderate and a score of 3 is severe [9].

The Diagnostic and Statistical Manual of Mental Disorders, $5^{\text {th }}$ Edition (DSM-V) has stated that there are various cognitive domains involved in cognition such as learning, memory, executive functioning, and motor ability [10]. The American Psychiatric Association has outlined the different domains and their different roles in the makeup of cognition. Executive functioning is involved in planning, decision making, working memory and responding to feedback. Memory is orientated around immediate, recent and long-term memory [10]. Therefore, due to the different functions of domains, in theory, the symptoms should be specific and applicable to each domain. For instance, it had been stated that the memory domain is one of the most important regarding medication adherence and administration [11]. However, Stoehr et al. [12] had put forward the theory that executive functioning plays a more vital role compared to memory regarding medication adherence. Similarly, external factors have been associated to medication adherence in cognitive impairment such as polypharmacy. However, the impact of this factor varied, for instance, it had been shown that the number of medications is not a substantial factor regarding medication adherence [12]. Although Stoehr found that less medication $(<5)$ resulted into greater adherence, this discrepancy in relation to the specific determinants that influence medication adherence in dementia, requires further investigation to ensure that the appropriate interventions can occur. Assessing the potential roles determinants play in dementia is crucial in order to minimize potential harm. Due to this gap in the knowledge, it is critical to further investigate this field and determine the extent to which determinants affect medication adherence as well as outline other external variables that may potentially influence medication adherence in those who are cognitively impaired with a dementia diagnosis.

\section{Aims}

The aim of this critical review was to explore the influence and extent to which dementia could potentially affect medication adherence behaviour.

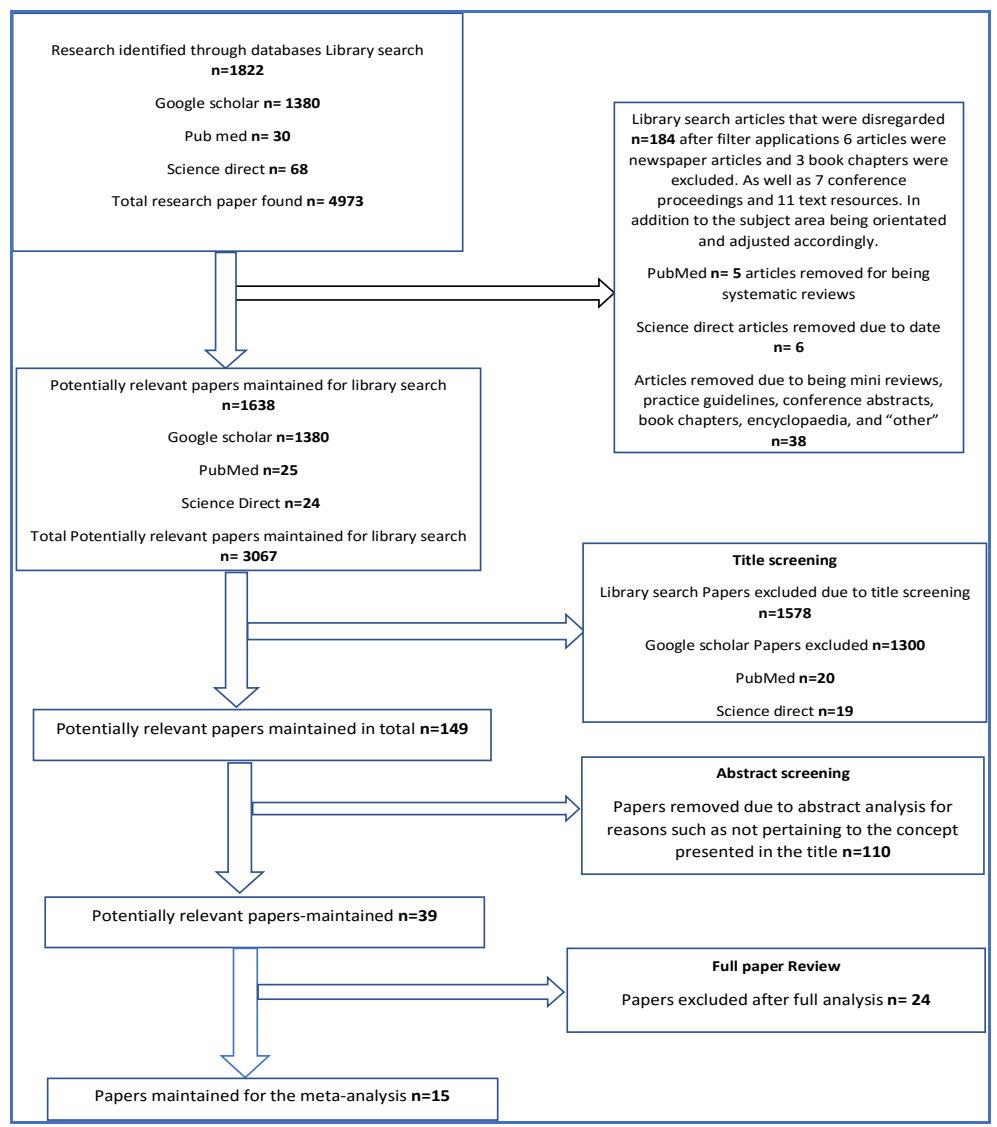

Fig. 1: Search strategy

\section{Methods and design}

\section{Search strategy and sample}

A search within ScienceDirect ${ }^{\circledR}, \quad$ PubMed $\AA$, Elsevier $\AA$ and Google ${ }^{\circledR}$ Scholarliterature databases, was performed in November 2019 using a combination of the following terms: <health determinants $>,<$ side effect $>,<$ medication adherence $>,<$ cognitive impairment $>$ and $<$ Caregivers $>$ (fig. 1). For a study to be included in the review, the following inclusion criteria were used:

1. Primary studies (not a systematic review or meta-analysis).

2. Full text is accessible. 
3. Primary outcome is one or all of the following:

a. One or more cognitive impairment determinants.

b. Dementia and its effects on medication adherence.

c. Medication adherence.

d. Caregivers' inclusion.

Randomized control trials were part of the inclusion criteria, including studies which used quantitative data/qualitative data. The following studies were excluded:

1. Small sample such as pilot studies.
2. Non-primary studies e. g. systematic reviews.

3. Non-English studies.

Studies dated over $20 \mathrm{y}$.

To assess the suitability of articles found via the search strategy; the Critical appraisal skills programme (CASP, casp-uk. net) tool was used to assess the integrity of the papers to ensure they were appropriate (Appendix 1).

The use of PICO (prisma-statement. org/) facilitated the search of similar papers as it allowed work to be orientated within a specific spectrum (table 1).

Table 1: The PICO model for clinical questions

\begin{tabular}{|c|c|c|}
\hline $\mathrm{P}$ & Patient, Population, or problem & Ranges from adults and the elderly \\
\hline I & Intervention, Prognostic Factor, or Exposure & The effect of different domains on medication adherence \\
\hline $\mathrm{C}$ & Comparison or Intervention (if appropriate) & $\begin{array}{l}\text { Comparison will involve the different domains and external factors that affect } \\
\text { medication adherence. }\end{array}$ \\
\hline \multirow[t]{3}{*}{0} & Outcome you would like to measure or achieve & $\begin{array}{l}\text { The outcome will revolve around the effects and extent of influences regarding the } \\
\text { domains and determinants }\end{array}$ \\
\hline & What Type of question are you asking? & The extent of influence of determinants on medication adherence. \\
\hline & Type of Study you want to find & Primary studies will be found to ensure the obtainment of first-hand data. \\
\hline
\end{tabular}

Regarding population, the studies obtained were mostly looking at middle-aged and/or older individuals rather than younger patients unless the study had looked at both. Similarly, specific disease states or those of similar characteristics e. g. 'cognition' were included.
Interventions included different cognitive domains, determinants of cognition, but all included assessment of cognition.

Fifteen studies were identified and included in this review (table 2).

Table 2: Final papers selected for the systematic review (Columns 2-5 are direct quotations from the published papers)

\begin{tabular}{|c|c|c|c|c|}
\hline Study & Study type & Sample & Results & Conclusion \\
\hline Doody, (2001) & $\begin{array}{l}\text { Open Label, } \\
\text { phase } 3 \text {, } \\
\text { double blind } \\
\text { study } \\
\text { Randomised } \\
\text { control study. }\end{array}$ & $\begin{array}{l}\text { Required to be } 50 \\
\text { years of age and } \\
\text { have completed } 1 \text { of } \\
2 \text { US Phase and } \\
\text { required to have had } \\
\text { a diagnosis of AD. }\end{array}$ & $\begin{array}{l}\text { Patients randomly assigned } 5 \mathrm{mg} \text { dose of } \\
\text { donepezil and placebo began to show } \\
\text { decline below at week } 12 \text {. Those randomly } \\
\text { assigned } 10 \mathrm{mg} \text { of donepezil began to show } \\
\text { decline at week } 36 \text {. }\end{array}$ & $\begin{array}{l}\text { Sustained treatment may confer some } \\
\text { advantages. Donepezil found to be an } \\
\text { effective and safe drug for long term } \\
\text { treatment for up to } 2.8 \text { years for mild } \\
\text { to moderately sever dementia. }\end{array}$ \\
\hline $\begin{array}{l}\text { Dolansky et al. } \\
\text { (2016) }\end{array}$ & $\begin{array}{l}\text { Cross } \\
\text { sectional } \\
\text { study }\end{array}$ & $\begin{array}{l}\text { Heart ABC enrolled } \\
372 \text { patients } \\
\text { recruited from } \\
\text { cardiology practices } \\
\text { in two major } \\
\text { hospital systems } \\
\text { opportunity sample }\end{array}$ & $\begin{array}{l}\text { Composite higher attention, executive } \\
\text { functioning and memory scores were } \\
\text { associated with greater medication } \\
\text { adherence. The relationship between } \\
\text { reduced memory and poorer medication } \\
\text { adherence remained significant in the } \\
\text { adjusted analysis ( } \beta=0.51, p=.008 \text { ) (Table } \\
\text { 3). }\end{array}$ & $\begin{array}{l}\text { There has been a highlighted } \\
\text { importance of considering a cognitive } \\
\text { function in the management of patients } \\
\text { with HF. Cognitive impairment and } \\
\text { memory, in particular, is associated } \\
\text { with with objectively monitored } \\
\text { medication adherence in patients with } \\
\text { heart failure. }\end{array}$ \\
\hline $\begin{array}{l}\text { Jeste et al. } \\
\text { (2003) }\end{array}$ & $\begin{array}{l}\text { Cross } \\
\text { sectional } \\
\text { study }\end{array}$ & $\begin{array}{l}\text { Opportunity sample } \\
\text { with a DSM-IV } \\
\text { diagnosis of } \\
\text { schizophrenia who } \\
\text { were participants in } \\
\text { the intervention } \\
\text { research centre for } \\
\text { psychosis in older } \\
\text { adults at the } \\
\text { university of } \\
\text { California }\end{array}$ & $\begin{array}{l}\text { Results } 1 \text { - found that better scores on the } \\
\text { dementia rating scale were associated to } \\
\text { better medication management ability scale. } \\
\text { DRS Conceptualisation score } 0.312^{* *} \text { and, } \\
\text { DRS memory } 0.275 \\
{ }^{*} \text { pV0.05. }{ }^{* *} \text { pV } 0.01\end{array}$ & $\begin{array}{l}\text { Cognitive functions, especially } \\
\text { conceptualization and memory, were } \\
\text { the strongest patient-related } \\
\text { predictors of his or her ability to } \\
\text { manage medications, over and above } \\
\text { the effects of age, gender, education } \\
\text { level, symptom severity, and attitudes } \\
\text { toward medications }\end{array}$ \\
\hline $\begin{array}{l}\text { El-Saifi, Moyle } \\
\text { and Jones } \\
(2018)\end{array}$ & $\begin{array}{l}\text { Cross } \\
\text { sectional } \\
\text { study }\end{array}$ & $\begin{array}{l}\text { Opportunity sample, } \\
\text { potential } \\
\text { participants were } \\
\text { invited through } \\
\text { leading caregiver } \\
\text { support agencies }\end{array}$ & $\begin{array}{l}\text { Those in profile one achieved a mean } \\
\text { adherence rate of } 0.69 \text { ( } 80 \% \mathrm{CrI}: 0.61- \\
0.77) \\
\text { those in profile } 2 \text { achieved of } 0.8(80 \% \mathrm{CrI} \text { : } \\
0.77-0.84)\end{array}$ & $\begin{array}{l}\text { Identified caregiver influence that } \\
\text { affect medication adherence }\end{array}$ \\
\hline $\begin{array}{l}\text { Austin et al. } \\
\text { (2017) }\end{array}$ & $\begin{array}{l}\text { Retrospective } \\
\text { analysis study }\end{array}$ & $\begin{array}{l}\text { Opportunity sample } \\
\text { recruited from local } \\
\text { retirement } \\
\text { communities for a } \\
\text { technology study }\end{array}$ & $\begin{array}{l}\text { Percentage of days where medications were } \\
\text { missed was not significant at the } 0.05 \text { level. } \\
\mathrm{P}=-0.63 \text {. The second model found that those } \\
\text { with a lower cognitive score would have } \\
\text { more spread in the timing of their } \\
\text { medication as it was found that for each } \\
\text { additional minute of spread ppts scored }\end{array}$ & $\begin{array}{l}\text { Concluded that ppts with higher } \\
\text { cognitive function are more regular } \\
\text { with the medication routine. Results } \\
\text { suggest that early detection of minor } \\
\text { cognitive impairment can be } \\
\text { established, }\end{array}$ \\
\hline
\end{tabular}




$\begin{array}{lll}\text { Hinkin et al. } & \begin{array}{l}\text { Cross } \\ \text { sectional } \\ \text { study. }\end{array} & \begin{array}{l}\text { convenience sample } \\ \text { of } 137 \text { HIV }\end{array} \\ & & \end{array}$

Lužný, Ivanovà and Juríčková (2014)

Thiruchselvam et al. (2014)

Foebel, Hirdes and Heckman (2012)

$\begin{array}{ll}\begin{array}{l}\text { Hayes et al. } \\ \text { (2009) }\end{array} & \begin{array}{l}\text { Cross } \\ \text { sectional } \\ \text { study }\end{array} \\ \begin{array}{l}\text { Ettenhofer et } \\ \text { al. }(2009)\end{array} & \begin{array}{l}\text { Cross } \\ \text { sectional } \\ \text { study }\end{array}\end{array}$

Chang et al. (2019)

$\begin{array}{ll}\text { Rovner and } & \text { Cross } \\ \text { Casten (2019) } & \text { sectional } \\ & \text { study }\end{array}$

Sirey et al. (2013)

\section{Cross} sectional study

Cross sectional study

Retrospective study patient aged 65 and more, first hospitalization of a senior due to dementia of any type and severity, diagnosis of dementia/ Opportunity sample Participants in this study were drawn from a prospective study of 365

Opportunity sample communities in

Oregon.

A volunteer sample of 431 HIV-infected adult

Observational, Opportunity retrospective database study of a populationbased cohort study

Crosssectional

Volunteer sample
Opportunity sample recruited from Thomas Jefferson university 2015-17
0.004 points lower on their cognitive $z$ score. $\mathrm{P}=0.014$

The mean adherence rate was $80.2 \%$. Only $34 \%$ took $95 \%$ of their prescribed dose. $47 \%$ of ppts were able to attain $90 \%$ of adherence rate. Cognitively impaired participants had lower adherence rates (73\%) than the cognitively intact group $(84 \%)[F(1,136)=20.39, p<0.001]$. A main effect for regimen complexity was also obtained $[\mathrm{F}(1,136)=11.12, \mathrm{p}=0.001]$

Non-adherence to psychiatric medication appeared in $38.1 \%$ of all non-adherent patients $(n=268)$. Main primary reason for non-adherence was that patient had forgotten if the prescribed drug was taken or not. Sensory impairment (especially visual disturbances) caused non-adherence to treatment in $14.2 \%$ of non-adherent patients

$17.4 \%$ ) had, at least, one report of medication nonadherence. Having at least one previous occurrence of medication nonadherence $(\mathrm{OR}=2.61 ; 95 \% \mathrm{CI}=1.18$ $5.62)$ and taking at least four medications (OR=2.58;95\%CI=1.31-5.29), both increased the odds by over 2.5 -fold.

The prevalence of HF among the sample was $15.5 \%$. while MCI was present in $42.3 \%$ of the sample. Among individuals with MCI, having a caregiver at the same residence reduced medication non-adherence.

Additionally, caregiver stress was significantly associated with higher rates of non-adherence

Convenience sample The LFC group had poorer performance on from two continuing the ADAS-COG score than the HFC group. care retirement (HCF: study
$6.0 \pm 2.1, \mathrm{LCF}: 9.9 \pm 2.1, \mathrm{t} 36=-5.81, \mathrm{p}$

$<.001)$.

executive functioning, motor functioning,

and processing speed were strongly related

to adherence in this age group.

neurocognitive impairment was associated with poorer medication adherence among older participants only

patients receiving oral rivastigmine had the highest PDC and MPR and had a significantly higher PDC compared with those receiving rivastigmine patch $(\mathrm{P}$ $<.001)$. Patients receiving donepezil had a those receiving rivastigmine patch $(\mathrm{P}$ $=.001$ ), whereas no significant difference was observed between the oral rivastigmine and donepezil groups $(\mathrm{P}=.195)$

$60.8 \%$ of participants were considered to be sub-optimally adherence $50.3 \%$ of participants (ppts) forgot to take their medication. $28 \%$ were being careless about taking their medication. $16.8 \%$ stopped taking medication when they felt better. Non-adherent participants had lower scores on living with daily activities as well as the belief that medicines may be harmful established on the BMQ.

More than one-third of the sample 41\% 122 of 299 reported at least 1 non-adherent behavior most common was forgetting to take medication; almost $10 \%$ of participants reported being careless. Older participants with a depression diagnosis were less adherent than those with no diagnosis significantly higher PDC compared with
Unexpectedly, there was a strong relationship between older age and better adherence patients age 50 and older were 2.9 times more likely to adhere than were younger subjects may be due to ranging and poor medication adherence may have multiple untoward clinical consequences, including cognitive decline

Non-adherence is great issue in the older population in those who suffer from dementia and can lead to the development of serious side effects and wrong therapy of the drug which may result into an increase in financial expenditure. A higher cognitive decline in a patient means a higher risk of nonadherence to treatment

Better conceptualization predicted non-adherence. poor memory and executive function, taking more than four medications, and at least one previous occurrence of medication nonadherence also increased the risk

Minor cognitive function can impair medication adherence and the presence of a caregiver is essential in the safety of the adult

very mild cognitive deficits may have a profound impact on medication taking, it is important that adherence during the trial be monitored closely if cognitive function is even mildly compromised. Older HIV-positive individuals with neurocognitive impairment or drug problems are at increased risk of suboptimal adherence to medication

Negative beliefs about medication as well as the emotional burden of living with another condition i. e diabetes and the ability to afford medication were related to suboptimal performance.

Results suggest that interventions to improve adherence should address various obstacles faced by older adults 


\begin{tabular}{|c|c|c|c|c|}
\hline $\begin{array}{l}\text { Sanborn, } \\
\text { Azcarate-Perril } \\
\text { and Gunstad } \\
(2019)\end{array}$ & $\begin{array}{l}\text { Parallel } \\
\text { randomized } \\
\text { controlled } \\
\text { trial }\end{array}$ & Opportunity sample & $\begin{array}{l}\text { Pearson correlation analysis showed Total } \\
\text { Cognition } \\
\text { Score was positively associated with total } \\
\text { adherence } \\
\text { (r } 1 / 40.21, \mathrm{p}<.01) \text {. }\end{array}$ & $\begin{array}{l}\text { The current study shows that poorer } \\
\text { performance on cognitive testing is } \\
\text { predictive of nonadherence in an RCT. } \\
\text { In addition to being vulnerable to } \\
\text { worse health outcomes. }\end{array}$ \\
\hline
\end{tabular}

\section{Data synthesis and analysis}

Common themes/domains were highlighted throughout these papers, which included reasons identified for non-adherence; simply forgot, cognitive deficitswhich included sensory impairment as well as executive functioning, polypharmacy and the role of caregivers. Regarding the theme of the patient/individuals simply forgetting their medication, several studies [13, 14, 20, 24, 25] categorised them as forgotten to take their medications due to:

\section{Cognitive impairment}

2. Disability

3. Mental illness

4. Simplyoccasionally forgetting to take their medication

Hinkin et al. [13] found that 75 participants believed that they had just forgotten to take their medication on several occasions [13]. Lužný, et al. [14] found that the primary reason for non-adherence was that patients did not know whether they had already taken their medication or not. However, this category may have been established due to self-reporting, as this was what the patients believed was the reason for their non-adherence, when in fact it may have been due to a more deep-rooted issue [14].

A further domain discussed is the impact of non-adherence in worsening cognitive function. Sanborn et al. [15] presented the theory of vulnerability becoming more prominent within patients as time progressed, in addition to their deteriorating health outcomes potentiated by non-adherence [15]. Similarly, Doody [16] highlighted the effects of worsening health outcomes from nonadherence and the lack of benefit resulting [16]. Lužný, [14] further expressed this theme, reporting that persistent nonadherence could lead to delusional or suspicious thoughts,in which the patient may refuse further medication.

Chang et al. [17] and Hinkin et al. [13] suggested that non-adherence may have multiple clinical consequences in addition to cognitive decline. Hinkin [13] also stated that being adherent resulted in a slower decline of multiple cognitive functional and global outcome measures. This theme was developed by Austin et al. [18], who suggested that these factors may be due to the increase of duration of ongoing medication. This provided a possible explanation and insight into a potential cause. The consistent themes identified were in relation to cognitive function and its constituents, attention, memory, executive functioning and their respective influences.

It has been shown that executive functioning has a predominant role in adherence, for example, Hinkin et al. discussed executive functions as a driving force in adherence and that this was apparent in previous work [13]. It was further developed by Ettenhofer et al., who also highlighted the importance of executive functioning through their findings [19]. However, memory and attention were not found to be significant in comparison to executive functioning and motor functioning. Thiruchselvam et al. [20] discovered poor performances on the DRS memory subscales lead to poor adherence, which opposed the findings of Ettenhofer et al. [19]. Both studies expressed the importance of executive functioning and its effects. Conversely, Hayes et al. (2009) found that the impact of memory planning and executive functioning were not as great as suggested in other studies [21]. This may imply that the extent or methodology in the use of tests may account for the differences in the effects of the different domains.

External factors regarding personal beliefs and co-morbidity were a further theme/domain highlighted. Ettenhofer, Rovner and Casten and Sirey et al. advanced the idea of co-morbidity affecting adherence [19, 22, 23]. For instance, Rovner found that the burden of living with more than one condition, which individually can worsen daily functioning, resulted into sub-optimal adherence [22]. They suggest that stressors of another condition can inadvertently affect adherence. In addition to this Rovner, Sireyand Thiruchselvam et al. also expressed that health beliefs about medication is a further theme $[22,23,20]$. Thiruchselvamdiscovered that patients who scored high on the dementia rating scale (DRS), a conceptualization subscale were found to be non-adherent [20]. This was attributed to the idea of concerns about their medication. Likewise, Rovner and Sireyfurther supported the idea of health beliefs potentially affecting adherence in cognitively impaired patients [22, 20].

Polypharmacy was considered a new theme, but the findings were more controversial. Dolansky et al. stated there was no significant relationship between the number of medications and the complexity of the regimen on medication adherence; however, it could be due to the complexity of medication being self-reported [24]. Comparably, Hayes found that polypharmacy had some effect, but the effect was not significant [21]. Thiruchselvam found taking more than 4 medications increased medication non-adherence by over 2.5-fold [20]. Austin et al. discussed the potential for polypharmacy to affect medication adherence; however, this was only indicated and not explicitly stated [18].

To add to this, caregivers were mentioned in few studies. For instance, Foebel, highlighted the fact that potential stressors can affect the caregiver, which then may result into non-adherence [25]. Similarly, Lužný, was the only researcher to examine this in depth [14].

\section{Level of bias}

The attainment of the graphs (fig. 3 and 4) below were developed using RevMan $5 \AA$. Within the application, a table was made for each separate paper. The table contained the domains present on the graph below in addition to the authors judgment and the support for judgment. CASP forms were completed as part of the process and the support for each judgment was given. This allowed the use of the labels "Low risk", "Unclear risk," and "Highest risk" for each study pertaining to each domain. Which resulted in the risk of bias and summary of bias graphs presented below.

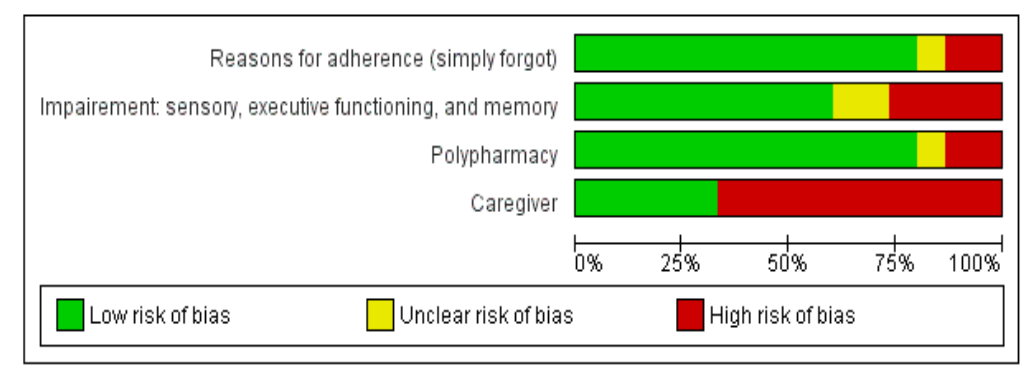

Fig. 2: Risk of bias presented as percentages across all included studies 


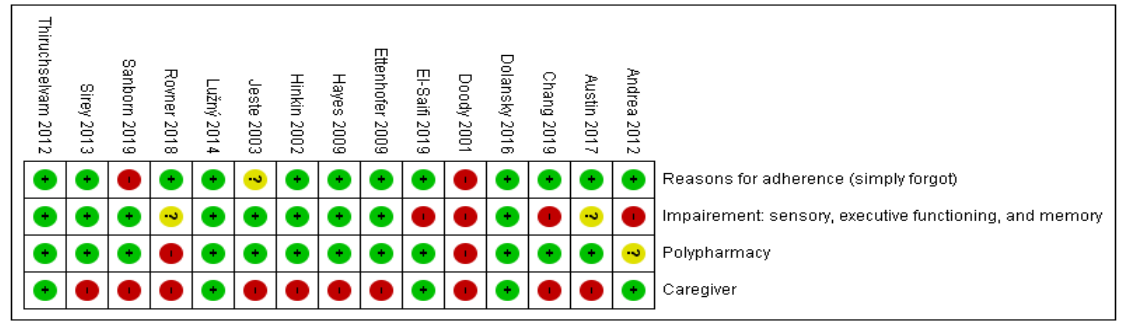

Fig. 3: Risk of bias summary

The effect of the depression domain within this study was debatable as the confidence interval had been placed in question. Executive functioning, memory and social support (caregiver) had a larger effect size and the confidence intervals were more reliable in comparison to depression (fig. 4).
Hinkin reported that the age group component had longest horizontal line, which indicates a lack of reliability in comparison to the rest of the factors that had been displayed [13]. Regimen complexity, psychiatric history, neurologic history and global neuropsychological impairment had more of a reliable effect (fig. 5).

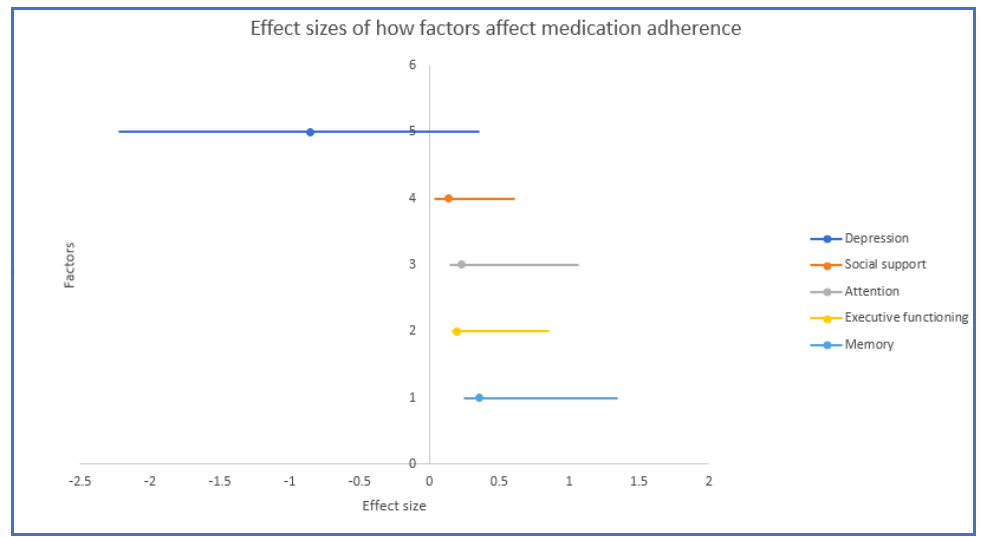

Fig. 4: Cognitive domains

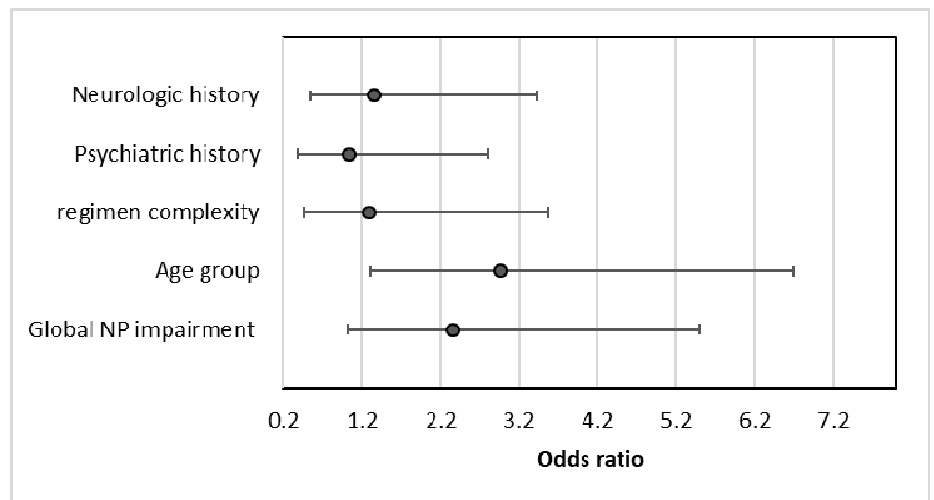

Fig. 5: Factors affecting adherence

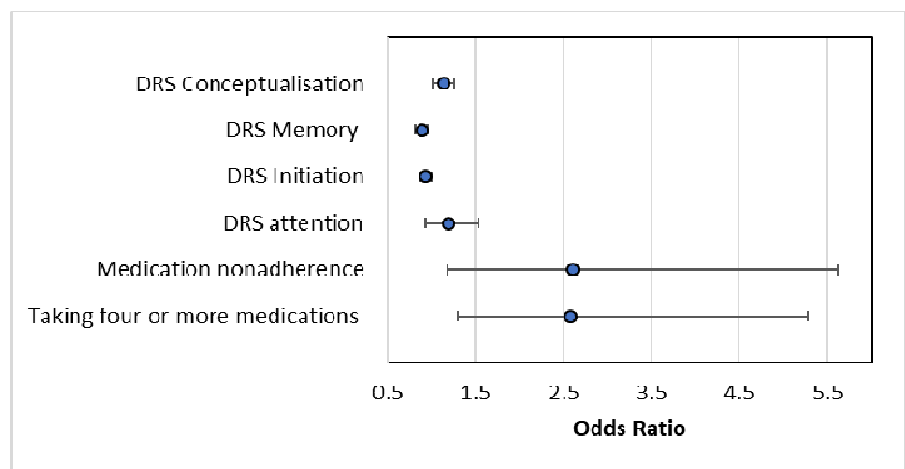

Fig. 6: Factors affecting adherence 
With respect to Thiruchselvam it had been shown that conceptualisation, memory, attention all had a significant impact on adherence furthermore, it had been clearly displayed that the results were reliable whereas polypharmacy had been questioned due to the wide confidence intervals (fig. 6) [20].

\section{Critical review}

It has been suggested that various cognitive domains may heavily influence medication no adherence. According to Smith et al. the "development of tailored interventions to combat non-adherence requires a better understanding of the potential contribution of cognitive domains" [26]. To truly understand the way in which cognitive impairment affects medication adherence, focus must be placed upon all present domains, to understand the impact each domain hason each other and on medication adherence. This study has shed light on the idea that the focus of studies to date is orientated upon two compartments which in this case is memory and executive functioning. Jeste $e t$ al. pointed that cognitive function was a significant predictor of medication management but did not fail to acknowledge other influencers [27]. In addition, Hinkin found that cognitively impaired patients on complex regimes had even greater difficulty adhering to medication. Suggesting that simplicity is crucial to try and achieve the best outcome [13].

It was found in all studies that no adherence can be predicted by the diagnosis of deficits in attention/mental flexibility and/or working memory [28]. Providing evidence to show other domains are associated. The authors also stated that impaired executive function was associated with poor adherence in one study out of the three.

Looking into memory and executive functioning it had also been found memory composite score did not predict adherence. This led to the suggestion that is likely to be more critical in less educated patients [29]. This may provide an explanation for the different results achieved by the various studies. The reason why executive functioning is examined thoroughly is because evidence has been shown that executive function is instrumental to medication adherence in addition to the daily activities that are carried out by the person [26]. However, this is not black and white since other studies have also shown that memory is substantially more important [24].

Additionally, it has been suggested that medication adherence in those who have dementia can be influenced by viainter and intrapersonal factors. Arlt, et al.(2008) stated they may be a reason why individuals with dysfunctional executive and memory functioning may not adhere to their medication due to these factors, which may have resulted from previous experiences.[30]This highlights the importance of this as it correlates with the caregiver due to the nature of cognitive decline, in disease progression. This study clearly placed importance of caregivers as responsible to ensure that the specified patient takes their medication. Accordingly, these intra and interpersonal factors evidently apply to the caregivers as well as patients. This was recently presented by ElSaifi et al. [31]. Who conducted a survey of 320 caregivers to determine influencers of medication adherence this study found that lower cognitive function of caregivers was a pivotal characteristic in the lower adherence group [31]. In a separate study El-Saifi et al. [32] stated that non-adherence may arise due to dementia patients displaying resistance which cements the importance of inter and intrapersonal factors [32].

Doody (2001) discussed the progressive cognitive decline in nonadherence, "After the 6-week placebo washout, the benefits of $24 \mathrm{w}$ of treatment with donepezil on cognition and global function were completely lost" which clearly establishes the link between medication adherence and prolonged cognitive function patients [16]. This shows that no adherence can potentially hasa knock-on effects as also by Lužný [14].

Several studies do not agree with Doody [16]. Maxwell et al. stated that there is uncertainty about the time when dementia medication should be discontinued because of a perceived lack of clinical benefit [33]. This statement highlights the idea of medication adherence being potentially detrimental in the long run as the patients do not experience alleviation regarding their clinical symptoms, which therefore suggests that they may be experiencing side effects. Furthermore, there is also the argument which is centred on the idea dementia medication ceases slowing down cognitive function at a certain point. Maxwell et al. found that patients were hospitalised with bradycardia whilst taking cholinesterase inhibitors which further stresses the idea of the dangers that may persist if benefits do not outweigh the risk [33]. This study ultimately discussed the dangers of the continuation of dementia medications, which most studies do not address or place focus upon. Further research is required to determine when it is appropriate to withdraw the medication. Furthermore, the continuation of active treatment may lead to hospitalisation and unnecessary cost.

Austin found that patients with mild cognitive impairment expected to take medication for longer time than those with severe symptoms, indicating that these patients will not be as adherent or consistent long term [18]. However, this study mostly used Caucasians hence lacking generalisability as it may not be applied to other ethnicitiess. Similarly, Elliott et al. concluded "that impaired cognition affects people's ability to manage regimes and increases the risk of errors "this coincides with the idea that decreasing cognitive function has a substantial impact on medication adherence [34]. Hawkins et al. made similar findings on a specific subpopulation [35]. Similarly, 38 participants who were ages $65 \mathrm{y}$ were placed into groups and it was found that a slight cognitive deficit led resulted into substantial impact in medication-taking [21].

Unlike other studies a link is made between the severity of dementia affecting medication adherence including an explanation for each stage, for instance in the early stages of the 57 participants interviewed dementia was characterised by resistance to maintain independence whereas in the later stages it is due to paranoia $[35,36]$. This alludes to the idea of a change in medicine management due to a change in behavioural patterns. This was further supported by Lim and Sharmeen who found that the difficulties of regimens increase with dementia progression due to a lack of internal memory cues [37]. Furthermore, regarding adherence most studies have looked at the concept that medication adherence decreases as the severity of dementia progresses. However, it has been suggested that the relationship between the two variables may be a U-shaped curve, where those with severe dementia rely on caregivers and those with mild dementia manage their medication on their own which results in increasing errors [38]. However, this topic has not been fully investigated and many outlying variables confound the results. A further confounder is that many of the studies are dated as most studies are dated as far back as 1994 .

\section{DISCUSSION}

The risk of bias regarding the different criteria selected varied, for instance; the potential effects of cognitive domains (sensory executive functioning and memory) had been outlined in most studies, but unclear definitions increase the risk of bias. This was attributed to either the researchers touching upon the subject but not explaining how it may have affected the study or the potential implications. Rovner and Casten acknowledged this but did not discuss this aspect thoroughly and instead placed more importance on the modifiable determinants of adherence such as daily functioning distress and affordability [22]. It was further acknowledged through the aspect of daily functioning, as this will involve abilities such as organisation planning and the ability to multitask, which are essential constituents of executive functioning. Therefore, inability to carry out these actions would suggest a deficit in the executive functioning domain. This, however, was not expressed and only indirectly implied, which led to the unclear risk of bias. Similarly, Austin et al. looked at cognitive function holistically but did not further digress into the potential importance of different domains and respective influences [18]. This is why the risk of bias was unclear.

When looking at the caregiver criteria this had the highest risk of bias in comparison to the rest of the comparators. This was mainly attributed to the fact that majority of the studies did not cover the potential influences or determinants that can affect caregivers or acknowledged caregivers as a determinant. This led to high risk associated within this domain due to the lack of ground covered. 
Three studies: Thiruchselvam, Lužný and Dolanskyhad the lowest risk of bias compared to others, as they outlined and expressed the significance of each domain $[20,14,24]$. For instance, the importance of memory was highlighted as a direct relationship between medication adherence and cognitive function. This was established once covariates were adjusted for Dolansky [24]. Similarly, executive function was associated with greater medication adherence however, once covariates were adjusted for the relationship was said not to be significant. The importance of caregivers was highlighted including the positive impact they have on medication adherence. Lužnýexpressed the importance of the memory domain in relation to medication adherence [14]. This was themost commonly expressed factor for non-adherencein addition to this the caregiver aspect was also established and the importance identified to medication adherence. It was also apparent for polypharmacy in all three reports. Ultimately this was significant as thorough identification occurred of certain determinants and medication adherence whilst also proposing explanations for possible causes. Hence the reason for the lowest risk of bias shared between all three studies.

Regarding bias, four studies had a low risk of bias as $75 \%$ of the domain's polypharmacy, simply forgetting, executive functioning, memory and sensory impairment criteria [19, 21, 13, 23]. Ettenhofer found that executive functioning was related to medication adherence in the elderly who were cognitively impaired; however the same did not apply to the younger group as there wasn't a relationship between cognition and adherence [19]. Whereas memory was found to not be significant in relation to adherence in older individuals and younger individuals. Similarly, the ideology of polypharmacy was touched upon and its influences discussed e. g. polypharmacy's the negative effect on the younger population. However, the caregiver domain was not touched, or its effects explained. Likewise, Hayes also expressed the importance of the three domains in a similar fashion and the importance of executive function; however, the caregiver aspect was not expressed [19]. This was also apparent for Hinkin, which is why in comparison to the three studies the low risk was slightly higher at $75 \%$, due to omissions of the caregiver aspect which is an influential factor in relation to medication adherence; providing an explanation for the rise in bias [35]. To expand, El-Saifi, had a similar risk of bias however, the caregiver domain had been thoroughly discussed and its effects explained [32].

Doody exhibited the highest risk of bias in comparison to the rest of the studies [16]. This may have been because of the nature of the study and participants taking part; for instance it is difficult to establish certain ideology/characteristics with randomised controls when looking at dementia patients. As this is a sensitive population, the use of cohort/prospective studies and those of a similar nature may be more applicable as more information can be obtained. In addition the nature of the Doody study was to look at the effects of the medication in that "specific population" which meant that a cause and effect relationship was the main factor that could have been drawn or taken away rather than the domains which may been inadvertently affected by the diminished cognition [16]. This explained the high risk of bias as none of the domains were touched upon or explained, only the establishment of the effects of medication adherence on cognition.

\section{CONCLUSION}

Overall, it may be concluded that the relationship between the levels of dementia prognosis (cognitive impairment) and medication adherence exist and that mental illness such as depression can add further complications. However, the study acknowledges that the caregiver involvement in the research needs to be addressed more appropriately in future research due to the high level of bias that was apparent within this study. More investigations are needed to identifying underlying factors that may potentially influence the level of adherence to therapy such as extrinsic and intrinsic factors. When looking at the different domains such as executive functioning, memory, attention and sensory impairment there was a slight variation regarding determinants and their respective influences especially around memory.
There were various discrepancies around this aspect, however, upon assessment, it is likely that variation can be attributed to the disease progression, which had not been previously stated.

\section{FUNDING}

Nil

\section{AUTHORS CONTRIBUTIONS}

All the authors have contributed equally.

\section{CONFLICT OF INTERESTS}

\section{Declare none}

\section{REFERENCES}

1. The World Health Organization (WHO). Adherence to longterm therapies evidence for action. Geneva: World Health Organization; 2003.

2. National institute of Clinical Excellence (NICE). Introduction | Medicines adherence: Involving Patients in Decisions about Prescribed Medicines and Supporting Adherence Guidance | NICE; 2009. Available from: https://www.nice.org.uk/ guidance/cg76/chapter/introduction [Last accessed on 21 Feb 2020].

3. Burnier M, Egan BM. Adherence in hypertension: a review of prevalence, risk factors, impact, and management. Circulation Res 2019;124:1124-40.

4. Ricci M. NHS to adopt Healthera's digital medicines adherence tools. Pharmaphorum. Available from: https://pharmaphorum.com/news/nhs-backed-healtheralaunches-medication-adherence-platform/ [Last accessed on 26 Aug 2019]

5. Dementia UK. What is front temporal dementia-Dementia UK. Available from: https://www.dementiauk.org/understandingdementia/types-and-symptoms/frontotemporal-dementia/. [Last accessed on 10 Dec 2019]

6. Dementia Statistics Hub. Prevalence | Dementia Statistics Hub. Available from: https://www.dementiastatistics.org/statisticsabout-dementia/prevalence/ [Last accessed on 25 Aug 2019]

7. Reed Guy L. The stages of dementia. Healthline; 2013a. Available from: https://www.healthline.com/health/dementia/stages\#stages [Last accessed on 25 Aug 2019]

8. Dementiacarecentral.com. Seven stages of dementia | symptoms, progression and durations; 2018. Available from: https://www.dementiacarecentral.com/aboutdementia/facts / stages/. [Last accessed on 10 Dec 2019]

9. Manning CA, Ducharme JK. Clinical dementia rating-an overview | ScienceDirect Topics. [online] Sciencedirect.com; 2010. Available from: https://www.sciencedirect.com/topics/neuroscience/clinicaldementia-rating [Last accessed 26 Aug 2019]

10. American Psychiatric Association, (2013). Diagnostic and Statistical Manual of Mental Disorders (DSM-5®). 5th ed. [online] Google Books. American Psychiatric Pub. Available at: https://books. google. co. uk/books?hl=enandlr=andid=JivBAAAQBAJandoi=fndandpg=PT18andots=ceVM_3QKxdandsi $\mathrm{g}=0 \mathrm{e} 02 \mathrm{ShXCTrpa30Y2jR0WsymC5IEandredir \_ esc=y \# v=onepa}$ geandqandf=false [Accessed 17 Feb. 2020].

11. Cho, M. H., Shin, D. W., Chang, S.-A., Lee, J. E., Jeong, S.-M., Kim, S. H., Yun, J. M. and Son, K. (2018). Association between cognitive impairment and poor antihypertensive medication adherence in elderly hypertensive patients without dementia. Scientific Reports, [online] 8, pp.1-7. Available at: https://www. nature. com/articles/s41598-018-29974-7 [Accessed 17 Feb. 2020].

12. Stoehr, G. P., Lu, S.-Y., Lavery, L., Bilt, J. V., Saxton, J. A., Chang, C.-C. H. and Ganguli, M. (2008). Factors associated with adherence to medication regimens in older primary care patients: The steel valley seniors survey. The American Journal of Geriatric Pharmacotherapy, [online] 6, pp.255-263. Available at: https://www. ScienceDirect. com/science/article/abs/pii/S1543594608000706?via\%3Dih ub [Accessed 17 Feb. 2020]. 
13. Hinkin, C. H., Castellon, S. A., Durvasula, R. S., Hardy, D. J., Lam, M. N., Mason, K. I., Thrasher, D., Goetz, M. B. and Stefaniak, M. (2002). Medication adherence among HIV+adults: Effects of cognitive dysfunction and regimen complexity. Neurology, [online] 59, pp.1944-1950. Available at: https://n. neurology. org/content/59/12/1944. short [Accessed 31 Aug. 2019].

14. Lužný, J., Ivanová, K. and Juríčková, L. (2014). NONADHERENCE IN SENIORS WITH DEMENTIA-A SERIOUS PROBLEM OF ROUTINE CLINICAL PRACTICE. Acta Medica (Hradec Kralove, Czech Republic), [online] 57, pp.73-77. Available at: https://actamedica. lfhk. cuni. cz/media/pdf/am_2014057020073. pdf [Accessed 26 Aug. 2019].

15. Sanborn, V., Azcarate-Peril, M. A. and Gunstad, J. (2019). The effects of medication adherence on study outcomes in randomized clinical trials: a role for cognitive dysfunction? Applied neuropsychology. Adult, [online] pp.1-6. Available at: https://www. ncbi. nlm. nih. gov/pubmed/31650861 [Accessed 24 Nov. 2019].

16. Doody, R. S. (2001). Open-Label, Multicenter, Phase 3 Extension Study of the Safety and Efficacy of Donepezil in Patients With Alzheimer Disease. Archives of Neurology, 58, p.427.

17. Chang CJ, Chou TC, Chang CC, Chen TF, Hu CJ, Fuh JL, et al. Persistence and adherence to rivastigmine in patients with dementia: results from a no interventional, retrospective study using the National Health Insurance research database of Taiwan. Alzheimer's and Dementia: Translational Research and Clinical Interventions 2019;5:46-51. Available from: https://www.sciencedirect.com/science/article/pii/S2352873 718300428 [Last accessed on 26 Aug 2019].

18. Austin J, Klein K, Mattek N, Kaye J. Variability in medication taking is associated with cognitive performance in nondemented older adults. Alzheimer's Dementia: Diagnosis Assessment Disease Monitoring 2017;6:210-3.

19. Ettenhofer ML, Hinkin CH, Castellon SA, Durvasula R, Ullman J, Lam $M$, et al. Aging, neurocognition, and medication adherence in hiv infection. Am J Geriatric Psychiatry 2009;17:281-90.

20. Thiruchselvam T, Naglie G, Moineddin R, Charles J, Orlando L, Jaglal S, et al. Risk factors for medication nonadherence in older adults with cognitive impairment who live alone. Int J Geriatric Psychiatry 2012;27:1275-82.

21. Hayes TL, Larimer N, Adami A, Kaye JA. Medication adherence in healthy elders. J Aging Health 2009;21:567-80.

22. Rovner BW, Casten RJ. Health beliefs and medication adherence in black patients with diabetes and mild cognitive impairment. Am J Geriatric Psychiatry 2018;26:812-6.

23. Sirey JA, Greenfield A, Weinberger MI, Bruce ML. Medication beliefs and self-reported adherence among communitydwelling older adults. Clin Thera 2013;35:153-60.

24. Dolansky MA, Hawkins MAW, Schaefer JT, Sattar A, Gunstad J, Redle JD, et al. Association between poorer cognitive function and reduced objectively monitored medication adherence in patients with heart failure. Circulation: Heart Failure 9; 2016.

25. Foebel AD, Hirdes JP, Heckman G. Caregiver status affects medication adherence among older home care clients with heart failure; 2012 Available from: https://www.semanticscholar.org/paper/Caregiver-statusaffects-medication-adherence-among-FoebelHirdes/d446fcf834fa5b3911c67d8b43eb32b6a43164d2 [Last accessed on 22 Oct 2019]

26. Smith D, Lovell J, Weller C, Kennedy B, Winbolt M, Young C, et al. A systematic review of medication non-adherence in persons with dementia or cognitive impairment. Plos One 2017a;12:e0170651.

27. Jeste SD, Patterson TL, Palmer BW, Dolder CR, Goldman S, Jeste DV. Cognitive predictors of medication adherence among middle-aged and older outpatients with schizophrenia. Schizophrenia Res 2003;63:49-58.

28. Stilley CS, Bender CM, Dunbar Jacob J, Sereika S, Ryan CM. The impact of cognitive function on medication management: three studies. Health Psychol: Official J Division Health Psychol Am Psychological Association 2010;29:50-5.

29. Insel K, Morrow D, Brewer B, Figueredo A. Executive function, working memory, and medication adherence among older adults. J Gerontol Series B: Psychol Sci Soc Sci 2006;61:P102P107.

30. Arlt S, Lindner R, Rosler A, von Renteln Kruse W. Adherence to medication in patients with dementia. Drugs Aging 2008;25:1033-47.

31. El-Saifi N, Moyle W, Jones C, Alston Knox C. Determinants of medication adherence in older people with dementia from the caregivers' perspective. Int Psychogeriatrics 2019a;31:335.

32. El-Saifi N, Moyle W, Jones C. Family caregivers' perspectives on medication adherence challenges in older people with dementia: a qualitative study. Aging Mental Health 2019b;23:1333-9.

33. Maxwell CJ, Stock K, Seitz D, Herrmann N. Persistence and adherence with dementia pharmacotherapy: relevance of patient, provider, and system factors. Canadian J Psychiatry 2014;59:624-31.

34. Elliott RA, Goeman D, Beanland C, Koch S. Ability of older people with dementia or cognitive impairment to manage medicine regimens: a narrative review. Curr Clin Pharmacol 2015;10:213-21.

35. Hawkins LA, Kilian S, Firek A, Kashner TM, Firek CJ, Silvet H. Cognitive impairment and medication adherence in outpatients with heart failure. Heart Andlung: J Critical Care 2012;41:572-82.

36. Kaasalainen S, Dolovich L, Papaioannou A, Holbrook A, Lau E, Ploeg J, et al. The process of medication management for older adults with dementia. J Nursing Healthcare Chronic Illness 2011;3:407-18

37. Lim RH, Sharmeen T. Medicines management issues in dementia and coping strategies used by people living with dementia and family carers: a systematic review. Int J Geriatric Psychiatry 2018;33:1562-81.

38. Rohde D, Merriman NA, Doyle F, Bennett K, Williams D, Hickey A. Does cognitive impairment impact adherence? A systematic review and meta-analysis of the association between cognitive impairment and medication non-adherence in stroke. Plos One 2017;12:e0189339. 